1 Universidade Federal da Paraíba (UFPB) - João Pessoa (PB), Brasil. Orcid: https://orcid. org/0000-0002-92189415

thuany_herc@hotmail.com

2 Universidade Federal da Paraíba (UFPB) - João Pessoa (PB), Brasil. Orcid: https://orcid. org/0000-0003-04395057

julianasmp@hotmail.com

3 Universidade Federal da Paraíba (UFPB) - João Pessoa (PB), Brasil. Orcid: https://orcid org/0000-0002-07640057

marita.med.ufpb@gmail.com

4 Universidade Federal da Paraíba (UFPB) - João

Pessoa (PB), Brasil.

Orcid: https://orcid.

org/0000-0003-4255-

9817

murillobraz14@gmail.com

\section{Doulas como gatilho de tensões entre modelos de assistência obstétrica: o olhar dos profissionais envolvidos}

\author{
Doulas as a tension trigger between obstetric assistance models: the \\ view of the professionals involved
}

Thuany Bento Herculano', Juliana Sampaio ${ }^{2}$, Marita de Almeida Assis Brilhante $\mathbf{3}^{\mathbf{3}}$ Murillo Bruno Braz Barbosa4

DOI: $10.1590 / 0103-1104201811813$

RESUMO Este artigo analisa a percepção dos profissionais de saúde da maior maternidade do estado da Paraíba acerca da inserção das doulas no processo de cuidado. Trata-se de estudo qualitativo, com 24 profissionais de saúde, cujo instrumento de coleta de dados foi uma entrevista semiestruturada. O papel da doula na assistência à parturiente foi descrito como: oferta de suporte emocional, físico e de informação. Cada uma dessas dimensões disparou tensões com diferentes personagens envolvidas no parto, como psicólogas, fisioterapeutas e médicas. Nesse cenário, as profissionais tencionam a delimitação de técnicas/conhecimentos privativos de cada categoria, a fim de ratificar sua autonomia frente ao surgimento de mais uma figura no cuidado à gestante, sobretudo quando essa personagem coloca em xeque práticas tradicionalmente executadas na obstetrícia. A gênese dessas tensões vai além da presença de um 'novo' sujeito na cena do parto, mas é um reflexo da conjuntura obstétrica brasileira, permeada por disputas entre modelos de assistência e por espaços de atuação. Também desperta a necessidade de construção de um cuidado compartilhado e centrado na parturiente.

PALAVRAS-CHAVE Doulas. Parto humanizado. Obstetrícia. Assistência perinatal.

ABSTRACT This article analyzes the perception of the healthcare professionals of the largest maternity of the state of Paraiba about the insertion of doulas in the care process. This is a qualitative study, with 24 health care professionals, whose instrument of data production was a semi-structured interview. The role of the doula in the assistance to parturient was described as: offer of emotional, physical and informational support. Each of these dimensions has triggered tensions with different characters involved in childbirth, such as psychologists, physiotherapists and physicians. In this scenario, professionals intend to delimit individual techniques/knowledge of each category, in order to ratify their autonomy in the face of the emergence of another figure in the care of the pregnant woman, especially when this character puts in check practices traditionally executed in obstetrics. The genesis of these tensions goes beyond the presence of a 'new' subject at the delivery scene, but it is a reflection of the brazilian obstetric scenario, permeated by disputes between care models and performance space. It also raises the need to build a shared care and centered on the parturient.

KEYWORDS Doulas. Humanizing delivery. Obstetrics. Perinatal care. 


\section{Introdução}

Nas últimas décadas, surgiram, em contrapartida ao modelo biomédico tradicional, iniciativas para reorientar a assistência prestada às mulheres no ciclo gravídico puerperal. Essas estratégias são conhecidas genericamente por humanização do parto e do nascimento. Entre elas, aparece o suporte contínuo durante o trabalho de parto, que pode ser realizado por profissionais do serviço, familiares ou acompanhantes leigas treinadas, conhecidas como doulas $\mathbf{1}^{\mathbf{1}}$.

A palavra 'doula' tem origem grega e significa 'mulher que serve'. Hoje, refere-se à pessoa com treinamento específico sobre fisiologia do parto normal, métodos não farmacológicos para alívio da dor, cuidados pós-natais e aleitamento materno. Ela oferece suporte emocional à gestante; traz conforto físico e alívio da dor, com massagens e banhos mornos; disponibiliza informações à gestante e seus familiares; e estabelece um vínculo entre a equipe de saúde e a mulher ${ }^{\mathbf{1}, 2}$.

No Brasil, a inserção das doulas, remuneradas ou voluntárias, dentro das maternidades, deu-se sem a participação dos profissionais atuantes no cenário do parto e, muitas vezes, sem o entendimento do seu escopo de atuação. Tal contexto abre margem para resistências e possíveis conflitos dentro das equipes de saúde, sobretudo porque grande parte das orientações oferecidas pelas doulas vão de encontro à predominante biomedicina intervencionista, o que transforma o trabalho de parto num cenário de disputa entre modelos de assistência ${ }^{2,3}$.

Frente a tal cenário, o presente estudo pretende analisar a percepção dos profissionais de saúde atuantes em uma maternidade pública da Paraíba acerca da inserção das doulas na assistência à mulher durante o trabalho de parto e parto, identificando o conhecimento sobre a função das doulas e possíveis benefícios, dificuldades e conflitos na participação destas no contexto obstétrico atual.

\section{Abordagem metodológica}

Trata-se de estudo descritivo-exploratório, de natureza qualitativa, realizado no Instituto Cândida Vargas (ICV), maternidade localizada no município de João Pessoa, que compõe a rede de serviços do Sistema Único de Saúde (SUS). Nela, existe, desde 2011, o Projeto de Doulas Voluntárias, criado pela Secretaria Extraordinária de Políticas Públicas para Mulheres (SEPPM). O projeto oferece um curso com duração de sete meses, sendo um mês de aulas teóricas, nas quais são abordados temas como: o trabalho da doula; voluntariado; ética profissional; dinâmica do parto; aleitamento materno; e práticas integrativas (exercícios preparativos para o trabalho de parto). Os outros seis meses são dedicados às atividades práticas no ICV, onde as doulas em formação trabalham diretamente com as mães e os profissionais da saúde 4 .

Os sujeitos do estudo foram 24 profissionais das diferentes categorias envolvidas na assistência ao parto no ICV: equipe de enfermagem (enfermeiros e técnicos de enfermagem), médicos, fisioterapeutas, psicólogos e assistentes sociais, no período de agosto de 2016 a abril de 2017. Como instrumento de coleta, foi utilizada a entrevista semiestruturada, que foi gravada e, posteriormente, transcrita na íntegra, preservando a identidade de seus participantes.

A pesquisa foi aprovada pelo Comitê de Ética em Pesquisa do Centro de Ciências da Saúde da Universidade Federal da Paraíba (CAAE - 56342016.5.0000.5188). As diretrizes que regulamentam as pesquisas envolvendo seres humanos, aprovadas pela Resolução do Conselho Nacional de Saúde (CNS) n ${ }^{0} 466 / 2012$, foram seguidas em todas as etapas deste estudo. Para garantir a confidencialidade, os trechos apresentados nos resultados foram identificados pela categoria profissional e numeração, de acordo com a ordem de realização da entrevista.

Todo o material produzido foi submetido à análise de conteúdo, através de três etapas: 
pré-análise, com repetidas leituras do corpus; exploração do material, identificando unidades de significado no conjunto das falas; e tratamento dos resultados com interpretação à luz do referencial teórico da pesquisa ${ }^{5}$.

As informações concernentes ao perfil do grupo estudado estão apresentadas em números absolutos e relativos. A partir da análise dos dados empíricos, surgiram três categorias: 'O papel da doula na assistência à parturiente'; 'Relação entre doula e equipe de saúde'; e 'Da inserção à regulamentação: processo, dificuldades e avanços'.

\section{Resultados e discussão}

\section{Perfil das profissionais de saúde entrevistadas}

As idades do grupo entrevistado variaram entre 26 e 65 anos (média $=43,3$ anos; $\mathrm{dp}=$ 13,8 anos). Todas as profissionais eram do sexo feminino. Quanto ao estado civil, 58,4\% $(n=14)$ das entrevistadas eram casadas e $66,7 \%$ $(\mathrm{n}=16)$ tinham filhos, com paridade média de 1,2 filhos. Com relação ao tipo de parto, houve predomínio da cesariana (68,7\%).

O tempo médio de formação dessas profissionais foi de 17,6 anos ( $\mathrm{dp}=14,2$ anos), sendo que o de atuação na obstetrícia foi de 16,7 anos ( $\mathrm{dp}=15,2$ anos); e, especificamente, no ICV, elas trabalhavam, em média, há 12,3 $\operatorname{anos}(\mathrm{dp}=11,2$ anos). A categoria com maior tempo de formação foi a equipe médica, com 35,1 anos. De modo análogo, trabalhavam na maternidade há mais tempo (23,8 anos).

No que se refere ao tempo de formação e de atuação na maternidade, o fato de a equipe médica ser mais antiga pode ter interferência no fato de ser a categoria profissional que apresentou maior resistência à presença das doulas, evidenciando tensões entre diferentes modelos de assistência obstétrica, como afirma esta médica pediatra a respeito das dificuldades que sua categoria apresenta:
[...] a maioria dos profissionais aqui é formada há muitos anos, quando não existiam essas coisas. O obstetra, que sempre foi o 'todo poderoso' da sala de parto, não está sabendo se posicionar frente a isso. (Médica Pediatra 9).

Contudo, essa resistência à adoção de novas práticas precisa ser pensada para além dos anos de formação, pois, ainda hoje, a formação médica em obstetrícia é centrada no domínio da técnica e no controle de riscos, em detrimento do processo fisiológico da parturição. Também não se privilegia o trabalho em equipe e a possibilidade de atuação de outras categorias na assistência ao parto, encarado como ato médico a ser realizado em ambiente hospitalar ${ }^{6}$.

No cotidiano dos serviços de assistência obstétrica, é possível perceber a polarização entre dois modelos: o biomédico, com foco nas patologias, ainda hegemônico; e a humanização, com uma proposta mais integrativa do processo de parir? ${ }^{7}$. Cabe situar que as doulas se consideram como representantes legítimas do movimento pela humanização do parto e do nascimento, e seu escopo de atuação se dá nessa seara de coexistência e polarização de modelos, por vezes, conflitantes ${ }^{8}$.

\section{O papel da doula na assistência à parturiente}

Segundo as profissionais entrevistadas, podem ser identificadas três dimensões de cuidado na atuação das doulas na maternidade, sendo que cada uma dessas dimensões dispara tensões com diferentes personagens envolvidas no cenário do parto hospitalar. Interessante notar que, quando questionadas sobre o que é uma doula ou quais seriam suas funções, as profissionais reafirmam o que elas são e o que é de sua competência fazer, no sentido de delimitar o que a doula 'não é' e 'não faz'.

A 'primeira dimensão', e mais citada, diz respeito à 'esfera emocional', na qual a doula oferece apoio, encorajamento e suporte 
emocional contínuos, o que acaba trazendo tranquilidade e segurança para a gestante.

Doula é uma mulher que cuida, que fica junto [...]. Ela fica com as pacientes no sentido de tranquilizar [...] como se dissessem: 'estou aqui o tempo todo'. (Psicóloga 3).

A partir de tal dimensão, observa-se uma tensão entre a função da doula e do acompanhante. A maioria das profissionais aponta que esse apoio é mais importante quando a mulher está sozinha, quando a doula funcionaria como uma acompanhante.

E a função do próprio acompanhante da pessoa? Pra que doula se você podia fazer um pré-natal de qualidade, treinando as pessoas que vão acompanhar essa paciente [...]. (Médica Pediatra 9).

Por outro lado, para uma minoria das entrevistadas $(n=4)$, a doula também se faz necessária dando suporte ao acompanhante escolhido pela parturiente. $\mathrm{O}$ reconhecimento do apoio da doula também à/ao acompanhante tem respaldo em estudos que mostram que, por estar envolvida/o emocionalmente com a gestante, por ser alguém de seu convívio familiar, que também precisa ser apoiado, este se diferencia da doula, que conseguiria manter-se tranquila nesse processo?.

Essa dimensão do cuidado também desperta tensões com as psicólogas, que buscam demarcar a diferença de seu papel, apontando que a função da doula não pode ser entendida como apoio psicológico, inerente ao saber da psicologia. Para elas, cabe às doulas um cuidado afetuoso, sem uma metodologia específica e cuja intervenção não busca alcançar um objetivo clínico determinado.

Apoio psicológico quem dá somos nós, psicólogos. Naquele momento, a doula está sendo humana [...] ela foi ali, fez uma escuta, e aquela mulher se acalmou. (Psicóloga 3).

A 'segunda dimensão' do cuidado atribuída às doulas diz respeito a intervenções na 'esfera física', a partir das quais as doulas utilizam métodos não farmacológicos para alívio da dor, como as massagens, e estimulam a deambulação, os exercícios e mudanças de posição. "As doulas fazem apoio para dor com massagem, exercícios e caminhada [...]" (Médica Pediatra 1).

Nessa dimensão do cuidado, a doula produz tensionamentos com a fisioterapia, na execução de exercícios, especialmente naqueles com uso da bola suíça e do balanço pélvico para parto (tipo 'cavalinho'), que, para as fisioterapeutas, seriam atribuições inerentes à sua categoria profissional.

[...] No início, tinha-se o medo da autonomia das doulas com relação aos exercícios [...] até porque existem aquelas pacientes que podem fazer e aquelas que não podem, então, isso aí a fisioterapia faz! (Fisioterapeuta 4 ).

Ao proporcionar conforto físico, seja através de compressas, massagens, uso da bola ou cavalinho, a doula permite que a mulher vivencie uma experiência de parto mais positiva. Tendo em vista custo e risco baixos, além da efetividade dessas medidas para o bem-estar materno, os métodos não farmacológicos são defendidos pela política de humanização para serem amplamente utilizados pela equipe que presta cuidado à gestante ${ }^{1,10}$.

Para as entrevistadas, a 'terceira dimensão’ da assistência prestada pelas doulas é o 'suporte de informações para a parturiente', através do qual a doula deve orientar como ocorre o trabalho de parto normal, evidenciando a fisiologia dos eventos vividos. Esse suporte de informações é apontado pelas profissionais como um instrumento para facilitar a aceitação do parto normal pela gestante e desmistificar as ideias construídas socialmente a respeito do parto vaginal, facilitando a rotina na maternidade.

A vivência do trabalho de parto normal é muito negativa para mulher pela falta de conhecimento.

Então, a doula consegue passar o conhecimento 
mínimo, e termina que a paciente aceita o trabaIho de parto, e transcorre tudo mais fácil. (Assistente Social 12).

Percebe-se, dessa forma, que, para as profissionais entrevistadas, a informação não deve ser passada no sentido de empoderar a parturiente para tomada de decisão, como aponta a literatura no tocante às funções da doula ${ }^{3,11}$, mas, sim, no sentido de docilizá-la frente às intervenções biomédicas. Para Foucault12(163), "é dócil um corpo que pode ser submetido, que pode ser utilizado, que pode ser transformado e aperfeiçoado".

A assistência ao parto, ao tornar-se ato médico e ser institucionalizada, passa a ser regida pela lógica do biopoder, cujo cerne é a promoção da vida. Dessa forma, o hospital, enquanto instituição disciplinar do biopoder, e o médico, seu principal agente, passam a ter livre acesso aos corpos, através de sua docilização e controle ${ }^{12}$. Nesse sentido, Simas ${ }^{9,13}$ observa que a gestante é tutelada pelo sistema médico hospitalar, em nome da manutenção da sua própria vida e do nascituro.

Na obstetrícia, isso se dá através do apelo à figura da mulher enquanto 'boa mãe', que para trazer seu filho ao mundo deve ser forte e aguentar a dor, de forma contida e parcimoniosa, o que é reforçado por profissionais que, conforme demonstram alguns estudos ${ }^{6,14}$, tratam pior as gestantes pouco colaborativas. Nesse contexto, em que o parto é permeado por expressões e sentimentos negativos, tais como dor e sofrimento, a doula teria, dentro desse cenário, uma 'missão positivadora' do trabalho de parto ${ }^{8}$.

As puérperas entrevistadas por Portela et al. $^{15}$ perceberam importantes inconsistências nas informações passadas entre os diferentes membros da equipe assistencial durante o parto, o que lhes proporcionou intensa insegurança. Para os autores, isso evidencia as falhas no processo de comunicação entre a equipe, assim como também reforça o quanto estamos distantes de um cuidado centrado na parturiente.
Destaca-se que nas três dimensões apontadas, todas as profissionais ressaltaram os limites de atuação das doulas e a necessidade de respeitar as atribuições de cada profissão na maternidade. Ressaltam que a presença de doulas se justificaria num contexto de carência ou despreparo dos profissionais, que fazem questão de ratificar não ser o caso da maternidade em questão.

Contudo, apenas entre as profissionais da categoria médica foi defendida a total dispensabilidade das doulas, já que, para elas, a doula não possui nenhuma função dentro da assistência ao parto, no contexto hospitalar e multiprofissional que se dispõe atualmente.

As doulas são múmias engessadas que roubavam crianças no século passado. Na verdade, esse era um termo pejorativo: $\delta o v \lambda \alpha$ (dula), que vem do grego e significa estar ao lado. Eram as criadas [...]. Para mim, doula não tem função [...]. (Médica Obstetra 17).

\section{Relação entre doula e equipe de saúde}

Para quem atua constantemente no pré-parto, especialmente para a equipe de enfermagem, 'há uma carência de profissionais para estarem junto às gestantes', justificando a presença de doulas. A equipe de enfermagem reconheceu a importância do suporte dado por elas, inclusive, alguns salientaram que essa dimensão do cuidado também é uma função da enfermagem, mas que, por conta da sobrecarga de trabalho em atividades técnicas, elas não podem dedicar-se exclusivamente a uma gestante, como as doulas fazem.

Quando elas não estão aqui, a gente sente muita falta, porque a gente não tem tempo de dar a assistência que as mulheres precisam no momento do trabalho de parto, a gente fica mais mecânica, na medicação e etc. [...]. (Técnica de Enfermagem 2). 
A enfermagem é um importante instrumento para efetivação das práticas obstétricas pautadas na humanização, já que esse tema é um importante norteador da formação desses profissionais ${ }^{16}$. Entretanto, o modelo de assistência das maternidades brasileiras impõe desafios ao enfermeiro, como a carga de trabalho excessiva e a falta de autonomia para que desempenhem um cuidado integral.

Para a enfermagem, a presença das doulas confere uma certa tranquilidade à equipe, pois elas comunicam qualquer necessidade da gestante. Entretanto, mesmo com esse reconhecimento, a maioria das profissionais da enfermagem apontou como ponto de conflito a interferência das doulas em condutas inerentes à enfermagem:

[...] estava prescrito ocitocina, e a minha função é fazer o que está prescrito, aí a doula disse: 'não coloca agora não a ocitocina, deixa eu trabalhar um pouquinho com ela'. (Técnica de Enfermagem 5).

Percebe-se uma tentativa de barganha das doulas com as enfermeiras e técnicas na execução de procedimentos contraindicados pela humanização, como o uso rotineiro de ocitocina sintética no trabalho de parto ${ }^{17}$. Essa realidade evidencia que se, por um lado, a doula tem acesso à enfermagem para dialogar e lutar em prol daquilo que julga melhor para a mulher, por outro, mostra uma equipe em que se estabelecem relações hierarquizadas e não dialógicas. Não há discussão de um plano de cuidado entre a equipe, tampouco com a gestante, principal interessada nesse processo, contrariando as diretrizes da política de humanização do SUS17.

Esse cenário é condizente com o modelo de assistência obstétrica tradicional, predominante no Brasil, no qual o cuidado está centrado no médico e dele partem as prescrições e intervenções. Essa organização do cuidado é resultado de uma formação calcada em complicações e riscos, e não no processo fisiológico de parturição ${ }^{9,18}$. Como alternativa a esse paradigma, o movimento de humanização propõe um modelo colaborativo de cuidado, com inserção de outros profissionais na assistência, tais como a enfermeira obstétrica, para condução dos partos de risco habitual, além das doulas, para oferecer apoio contínuo à gestante ${ }^{19}$.

Segundo Portela et al. ${ }^{15}$, ainda estamos distantes da efetivação de um modelo colaborativo na assistência obstétrica brasileira. Configuram-se como nós críticos a dificuldade de redistribuição de poder, a necessidade de construção de relações de confiança entre os membros da equipe e a desmistificação de que a intervenção profissional é sempre benéfica.

As profissionais entrevistadas ressaltaram que não é papel das doulas envolverem-se em questões técnicas, que devem ficar a cargo da equipe de saúde. Essa tensão explicita os desafios da produção das práticas interprofissionais, tendo em vista que

a complementaridade e interdependência entre os trabalhos especializados da equipe de saúde estão com frequência em tensão com a autonomia técnica que os profissionais buscam ampliar20(1427).

Em oposição ao que foi apresentado pela enfermagem, para as profissionais, especialmente as médicas obstetras e pediatras, que atuam somente na cena do parto, que, via de regra, ocorre no bloco cirúrgico ou na sala de parto, a maternidade 'enfrenta um excesso de pessoas':

Eu acho um circo, dentro de uma sala de parto [...] o obstetra, o pediatra, o psicólogo, o fisioterapeuta, o acompanhante, a doula, os técnicos de enfermagem e os estudantes [...] ou dispensa a doula ou um desses profissionais, para elas poderem atuar [...]. (Médica Pediatra 9).

Tal realidade nos leva a crer que o cerne do problema é que se negligencia o processo (partejar) em favor do desfecho (parto), pois, ao passo que se encontram mulheres 
sozinhas no pré-parto, sobretudo as mais pobres e de cidades do interior, na hora do nascimento, há um grande contingente de pessoas, o que pode ser justificado pela percepção desta profissional: "partejar não é a função dos profissionais, pois eles executam técnicas e procedimentos, cabendo isso à doula" (Psicóloga 24).

Todavia, cabe considerar que o grande contingente de pessoas na cena do parto não representa necessariamente melhoria na assistência. Muito pelo contrário, o cuidado não confidencial ou privativo faz parte do arsenal da violência obstétrica, o que está relacionado com pior satisfação da parturiente à assistência prestada, sobretudo quando os profissionais não agem de forma coesa ${ }^{21}$.

Percebe-se, ainda, uma necessidade de marcar a distinção entre o 'meu' saber/ fazer, dotado de cientificidade e respaldado por anos de estudo, do saber/fazer da doula, marcado por um caráter subjetivo, intuitivo, não técnico e, portanto, substituível e, por vezes, dispensável. Há, então, uma intensa polarização entre cuidado (humanizado) e assistência técnica.

Evidencia-se, ainda, intensa dificuldade em estabelecer um diálogo entre doulas e profissionais:

[...] eu só converso com meus pares. Se ela não tem o curso como eu, ela não vai ter nunca condição de discutir comigo, nem de questionar a conduta médica. (Médica Obstetra 15).

Para Watson et al. $\mathbf{2 2}$, a comunicação efetiva é um passo fundamental para alcançar o trabalho interprofissional na obstetrícia. Entretanto, esse diálogo pode ser dificultado por visões de mundo antagônicas sobre gestação e nascimento, pois se, de um lado, o parto é tido como um evento arriscado que precisa de intervenção precoce e aparato médico-tecnológico, do outro, trata-se um evento fisiológico, que necessita do mínimo de intervenções em grande parte dos casos.

Para as profissionais, a presença da doula é benéfica até o ponto que não coloca em xeque as suas práticas, e isso é marcante no discurso médico, talvez pela característica da formação, que, historicamente, colocou esse profissional como o condutor da assistência?.

Elas instigam as pacientes contra os profissionais [...]. Geram animosidade entre as partes, repercutindo negativamente na paciente, que dá mais importância a elas do que a gente [...], elas interpretam condutas médicas como violência obstétrica. (Médica Obstetra 17).

Na percepção das entrevistadas, doulas e profissionais conviveriam 'harmonicamente' se uma não interferisse na prática da outra, o que contribui para um cuidado demasiadamente fragmentado. "Cada um no seu quadrado!” (Técnica de Enfermagem 7 e 10).

Para garantir uma assistência à gestação e ao parto bem-sucedida, é necessária a construção de práticas colaborativas, nas quais há interação entre conhecimentos, especialidades, experiências e habilidades, numa perspectiva humanista. Nesse ínterim, pode ser que a delimitação precisa de atribuições seja complicada e, por essa razão, seja necessário que o profissional tenha mais tolerância em lidar com situações ambíguas, sem perder o foco na qualidade e na segurança do cuidado. $\mathrm{O}$ cerne da assistência obstétrica deve ser o trinômio mãe-bebê-família, e, para tal, o trabalho em equipe precisa se impor 15,23 .

De modo geral, há uma percepção de que a doula deve estar a serviço da instituição e dos seus profissionais. Apenas três profissionais afirmaram que a necessidade ou dispensabilidade de uma doula deveria ficar a critério da gestante no exercício de sua autonomia e protagonismo, um dos pilares da humanização do parto e do nascimento ${ }^{17}$.

Apesar de iguais no gênero, parturientes, doulas e as profissionais entrevistadas são desiguais nas relações de poder. Essa desigualdade está subsidiada nas diferenças socioeconômicas e étnicas, bem como no domínio do conhecimento técnico e 
científico das profissionais, e sustentada na ideologia naturalizada de um saber médico salvador, capaz de intervir sobre o corpo através do domínio das tecnologias duras ${ }^{9,13}$.

\section{Da inserção à regulamentação: pro- cesso, dificuldades e avanços}

No tocante à inserção das doulas na maternidade, percebe-se que nenhuma categoria profissional participou efetivamente desse processo. A categoria que mais buscou essa aproximação foi a enfermagem.

Em 2010, teve o primeiro Congresso das Doulas que eu participei [...] a partir daí, a Secretaria de Saúde começou a ter um olhar diferenciado para que fossem colocadas aqui na maternidade [...]. (Enfermeira 14).

Dessarte, não há a compreensão de que a introdução delas na assistência às mulheres em trabalho de parto foi algo inerente às necessidades de construção de uma equipe multiprofissional nem que atendia ao novo paradigma de cuidado que se estava tentando implantar no serviço. "[...] Muitos profissionais acham que foi algo da política e não veem como uma necessidade para melhoria da assistência" (Enfermeira 18).

Todavia, depois que as mudanças já estavam instaladas e interferindo diretamente nas condutas profissionais, elas passaram a questionar a legitimidade da nova personagem no cenário da maternidade e a buscar estratégias de enfrentamento e delimitação de espaços de atuação. Para as profissionais, especialmente as médicas, o principal ponto de questionamento foi não ter havido participação da categoria para avaliar a necessidade, delimitar funções e estabelecer protocolos.

[...] Eu não lembro de ter havido uma discussão prévia para saber da opinião da gente [...] é a enfermagem e as doulas que participam [...] ]estão bem mais informadas que os médicos e os outros profissionais. Então, médico está totalmente por fora. (Médica Obstetra 8).
Em estudos realizados com as profissionais de enfermagem, foi observado que, apesar destas identificarem inúmeros benefícios na inserção das doulas na assistência à parturiente, também há uma série de dificuldades no cotidiano do trabalho, decorrentes da falta de participação das profissionais no processo de decisão, treinamento e inserção das doulas. Para os autores, isso contribui para a rejeição e até mesmo resistência à inserção das doulas, já que esta não foi compreendida coletivamente como uma estratégia de melhoria da qualidade da assistência, sendo vista como uma medida imposta pela instituição $0^{\mathbf{2} 24}$.

No que se refere aos critérios de seleção para participar do curso de Doulas Voluntárias do ICV e, posteriormente, atuar na maternidade, as profissionais mostram desconhecimento e afirmam não terem sido comunicadas/envolvidas nesse processo. Foram apontados o fato de que deveriam ser 'mulheres de comunidade', com tempo e disposição para o trabalho voluntário, e que não poderiam fazer parte do quadro de funcionários do município. A questão de não ser necessário como pré-requisito ter engravidado/parido foi um ponto de questionamento da legitimidade do trabalho desempenhando pelas doulas apresentado pela categoria médica.

Se a doula é uma pessoa de experiência no ofício, como é que a pessoa que nunca teve um parto, nunca assistiu um parto pode saber conduzir uma paciente? [...] Mulheres sem experiência querendo ensinar o que não sabem! (Médica Obstetra 17).

No Brasil, as organizações representativas das doulas elencam como pré-requisitos para tornar-se doula: a disponibilidade de horário; ter o apoio do companheiro e dos familiares; ter outra doula para realizar permuta em caso de necessidade; e ter alguma base material para custear a formação e o constante aperfeiçoamento em formação complementar. No tocante à maternidade, é preferível 
que já seja mãe e que sua experiência de parto tenha sido satisfatória ou, pelo menos, que tenha trabalhado suas frustrações antes de atuar como doula ${ }^{8}$.

É importante pontuar o paradoxo existente na atuação da doula, pois esse constante aperfeiçoamento pode aproximá-la do saber técnico-científico e da profissionalização, o que, em primazia, não é sua essência. Para Fleischer8(20), "a doula trafega em meio às dicotomias, ora calcada na técnica e na cultura, ora respaldada pela inspiração e a natureza".

Apesar do slogan reiteradamente utilizado pelos ativistas da humanização de que 'Doula não faz parto, faz parte', há sim um embate no campo técnico com os profissionais, como expresso mais fortemente na fala das psicólogas e fisioterapeutas. Para os demais profissionais, isso também é sentido, já que, como confirma a literatura, a própria presença da doula tem impacto no desfecho da assistência, com redução das cesarianas, maior contato pele a pele entre mães e bebês e maior satisfação das usuárias ${ }^{25}$.

Percebe-se uma dificuldade das profissionais em avaliar as mudanças na assistência obstétrica após a chegada das doulas na maternidade, apesar de já ser uma realidade há mais de 6 anos. Como principal justificativa para isso, apontam a falta de regularidade na presença delas, pois a maternidade não conta com doulas todos os dias, e observa-se um esvaziamento após a conclusão do estágio obrigatório. "Se tem doula, é para ter doula todos os dias, não só esporadicamente [...] eu acho que o que falta é isso: ser uma rotina!" (Fisioterapeuta 4).

Há uma grande resistência das equipes de saúde em reconhecer a contribuição das doulas no cuidado à parturiente, repercutindo na invisibilidade dessas personagens na cena do parto. Para muitas doulas, tal condição termina sendo algo benéfico, pois lhes permite atuar junto à gestante com discrição e sem tantas interferências ${ }^{8}$.

As profissionais demandam, ainda, a necessidade de haver uma escala de plantão para doulas, assim como há para os profissionais. Entretanto, nem todas as entrevistadas sabem que se trata de um trabalho voluntário, não havendo nenhuma ajuda de custo para transporte ou alimentação.

Isso é cabide de emprego [...] eu não tenho certe$z a$, acredito que sejam funcionárias contratadas [...] não sei se vem uma remuneração específica do Ministério da Saúde [...]. (Médica Obstetra 9).

Esse esvaziamento, após o estágio obrigatório, também pode ser sintomático da dificuldade de aceitação das doulas pela equipe, pois percebe-se concentração de doulas em alguns dias específicos da semana, cujos profissionais de plantão mostram um melhor relacionamento com elas. Percebe-se que

num cenário hostil à sua atuação, as doulas, no lugar de funcionarem como dispositivos para melhoria da qualidade da assistência, muitas vezes, são gatilhos de embates e de produção de mais violência, e isso produz sofrimento nelas e nos demais envolvidos ${ }^{26(428)}$

Nota-se que há uma tentativa de desqualificação da figura da doula, que permeou esta e as outras categorias temáticas geradas. Tal fato se dá por ser a doula uma representante da comunidade inserida na rotina hospitalar dominada pelo saber biomédico e sua cientificidade. Bem como justifica-se pela natureza do trabalho da doula apropriar-se de elementos, muitas vezes, marginalizados pela ciência e não trabalhados na formação biomédica ${ }^{24}$.

A partir desse cenário, Merhy e Feuerwerker ${ }^{27(39)}$ entendem que:

o território das práticas de saúde é um espaço de múltiplas disputas e de constituição de políticas desenhado a partir da ação de distintos atores, que, dependendo de seus interesses e capacidade de agir, aliam-se ou confrontam-se na tentativa de afirmar uma certa conformação da saúde que faça sentido. 


\section{Considerações finais}

Ao analisarmos a relação das doulas com as diferentes categorias profissionais, percebe-se que a gênese dessas tensões vai muito além da presença de um ‘novo' sujeito na cena do parto. A realidade local é um reflexo da atual conjuntura obstétrica brasileira, permeada por disputas entre diferentes modelos de assistência e por espaço de atuação.

Dessa forma, seria aceitável para os profissionais se essa 'nova' personagem não colocasse em xeque saberes e práticas consolidados na obstetrícia tradicional. Ao passo que os profissionais que afirmam que elas não têm qualificação técnica para discutir condutas ou questionar práticas corroboram a necessidade de que mantenham-se leigas e afastadas do conhecimento científico que compete a eles.

Portanto, na visão de boa parte dos profissionais, especialmente da categoria médica, a presença da doula seria justificável num contexto de mulheres sozinhas, desinformadas e que precisam mostrar mais aceitação ao trabalho de parto normal e às normas e rotinas hospitalares, bem como à conduta pessoal de cada profissional.

O desconhecimento das singularidades do trabalho da doula acaba perpetuando tensões e conceitos conflituosos, tais como: a dispensabilidade do fisioterapeuta ou do psicólogo na presença da doula; a necessidade de escolher entre o acompanhante familiar ou a doula; e, ainda, a falta de utilidade em haver alguém específico para oferecer apoio à gestante. Para alguns profissionais, esse seria um papel da enfermagem, não sendo reconhecido que o toque, a escuta e o apoio são inerentes ao cuidado em saúde, seja ele desempenhado por qualquer profissional.

A doula, que figura no movimento da humanização do parto como uma personagem existente para trazer tranquilidade e conforto à parturiente, funcionou como mais um elemento de instabilidade no cenário analisado, que já apresentava dificuldades no trabalho em equipe e embate entre o modelo assistencial da humanização e aquele no qual a maioria dos profissionais foi formada e atuava desde então.

Essa realidade aponta para a necessidade de repensarmos a assistência obstétrica, desde a formação dos profissionais, para que seja possível um cuidado compartilhado e solidário, centrado na mulher, que rompa com os limites de práticas privativas dessa ou daquela profissão.

\section{Colaboradores}

Herculano TB contribuiu para a concepção e planejamento da pesquisa; análise e interpretação dos dados; elaboração do manuscrito; e aprovação da versão submetida à revista. Sampaio J contribuiu para a concepção e planejamento do projeto de pesquisa; análise dos dados; revisão crítica do manuscrito; e aprovação da versão submetida à revista. Brilhante MAA contribuiu para o planejamento do projeto de pesquisa; análise e interpretação dos dados; revisão crítica do manuscrito; e aprovação da versão submetida à revista. Barbosa MBB contribuiu para o planejamento do projeto de pesquisa; análise dos dados; revisão crítica do manuscrito; e aprovação da versão submetida à revista. 


\section{Referências}

1. Bohren MA, Hofmeyr GJ, Sakala C, et al. Continuous support for women during childbirth. Cochrane Database Syst Rev. 2017; 7:1-169.

2. Santos DS, Nunes IM. Doulas na Assistência ao Parto: Concepção de Profissionais de Enfermagem. Esc Anna Nery. 2009; 13(3):582-588.

3. Leão MRC, Bastos MARB. Doulas apoiando mulheres durante o trabalho de parto: experiência do Hospital Sofia Feldman. Rev Latinoam Enferm. 2001; 9(3):90-94.

4. Paraíba. Prefeitura Municipal de João Pessoa. Portal de Notícias [internet]. João Pessoa: Prefeitura Municipal; 2018 [acesso em: 2017 maio 9]. Disponível em: http://www.joaopessoa.pb.gov.br.

5. Minayo MCS. O desafio do conhecimento: pesquisa qualitativa em saúde. 7. ed. São Paulo: Hucitec; 2000.

6. Souza AB, Silva LC, Alves RN, et al. Fatores associados à ocorrência de violência obstétrica institucional: uma revisão integrativa da literatura. Rev Ciênc Méd. 2016; 25(3):115-128.

7. Mendonça SS. Modelos de assistência obstétrica concorrentes e ativismo pela humanização do parto. Civitas. 2015; 15(2):250-271.

8. Fleischer S. Doulas como 'amortecedores afetivos': Notas etnográficas sobre uma nova acompanhante de parto. Rev Ciênc Soc Unisinos. 2005; 41(1):11-22.

9. Simas R. Doulas e o movimento pela humanização do parto: poder, gênero e a retórica do controle das emoções [dissertação]. Niterói: Universidade Federal Fluminense; 2016.

10. Mafetoni RR, Shimo AKK. Métodos não farmacológicos para alívio da dor no trabalho de parto: revisão integrativa. REME Rev Min Enferm. 2014; 18(2):505-520.
11. Latorre VV, Huaquin XM. Aportes de las doulas a la obstetricia moderna. Rev Chil Obstet Ginecol 2005; 70(2):108-112.

12. Foucault M. Vigiar e punir: nascimento da prisão. Petrópolis: Vozes; 1987.

13. Simas R, Mendonça SS. O caso Adelir e o movimento pela humanização do parto: reflexões sobre violência, poder e direito. Vivência: Rev Antropol. 2017; 1(48):89-103.

14. Aguiar JM, d'Oliveira AFPL, Schraiber LB. Institutional violence, medical authority, and power relations in maternity hospitals from the perspective of health workers. Cad Saúde Pública. 2013; 29(11):2287-2296.

15. Portela MC, Reis LGC, Martins M, et al. Cuidado obstétrico: desafios para melhoria da qualidade. Cad Saúde Pública. 2018; 34(5):1-3.

16. Ferreira Júnior AR, Makuch MY, Osis MJMD, et al. Percepções de profissionais de enfermagem sobre a humanização em obstetrícia. Sanare. 2015; 14(2):2735.

17. Brasil. Ministério da Saúde. Caderno Humaniza SUS: humanização do parto e do nascimento. Brasília, DF: MS; 2014.

18. Araújo D, Miranda GCM, Brasil LS. Formação de profissionais de saúde na perspectiva da integralidade. Rev Baiana Saúde Pública. 2007; 31(1):20-31.

19. Vogt SE, Silva KS, Dias MAB. Comparison of childbirth care models in public hospitals, Brazil. Rev Saúde Pública. 2014; 48(2):304-313.

20. Angulo-Tuesta A, Giffin K, Gama AS, et al. Cooperation and conflict in childbirth care: representations and practices of nurses and obstetricians. Cad Saúde Pública. 2003; 19(5):1425-1436.

21. Tesser DC, Knobel R, Aguiar FHA, et al. Violên- 
cia obstétrica e prevenção quaternária: o que é e o que fazer. Rev Bras Med Fam Comunidade. 2015; 10(35):1-12.

22. Watson BM, Heatley ML, Gallois C, et al. The importance of effective communication in interprofessional practice: perspectives of maternity clinicians. Health Commun. 2016; 31(4):400-407.

23. Furtado JP. Arranjos institucionais e gestão da clínica: princípios da interdisciplinaridade e interprofissionalidade. J Ment Health. 2011; 1(1):178-189.

24. Wolfe KS. A Doula Can Only Do So Much: Birth Doulas and Stratification in United States Maternity Care. Digital Commons. 2015; 37:1-104.

25. Soares RS, Albuquerque A, Anjos UU, et al. Analysis Infuence in Childbirth Care on the Doulas at a Maternity. Intern Archives Med. 2016; 9(269):1-6.
26. Barbosa MBB, Herculano TB, Brilhante MAA, et al. Doulas como dispositivos para humanização do parto hospitalar: do voluntariado à mercantilização. Saúde Debate [internet]. 2018 [acesso em 2018 jul 15]; 42(117):420-429. Disponível em: http:// www.scielo.br/pdf/sdeb/v42n117/0103-1104sdeb-42-117-0420.pdf.

27. Merhy EE, Feuerwerker LCM. Novo olhar sobre as tecnologias de saúde: uma necessidade contemporânea. In: Mandarino ACS, Gomberg, E, organizadores. Leituras de novas tecnologias e saúde. Bahia: UFS; 2009. p. 29-56.

Recebido em 08/02/2018

Aprovado em 31/07/2018

Conflito de interesses: inexistente

Suporte financeiro: não houve 